\title{
Postoperative elective pelvic nodal irradiation compared to prostate bed irradiation in locally advanced prostate cancer - a retrospective analysis of dose-escalated patients
}

Carola Link ${ }^{1 \dagger}$, Patrick Honeck ${ }^{2 \dagger}$, Akiko Makabe ${ }^{1}$, Frank Anton Giordano ${ }^{1}$, Christian Bolenz ${ }^{3}$, Joerg Schaefer ${ }^{1}$, Markus Bohrer ${ }^{1}$, Frank Lohr ${ }^{4}$, Frederik Wenz ${ }^{1,5}$ and Daniel Buergy ${ }^{1,6^{*}}$

\begin{abstract}
Background: It is uncertain if whole-pelvic irradiation (WPRT) in addition to dose-escalated prostate bed irradiation (PBRT) improves biochemical progression-free survival (bPFS) after prostatectomy for locally advanced tumors. This study was initiated to analyze if WPRT is associated with bPFS in a patient cohort with dose-escalated (> 70 Gy) PBRT.

Methods: Patients with locally advanced, node-negative prostate carcinoma who had PBRT with or without WPRT after prostatectomy between 2009 and 2017 were retrospectively analyzed. A simultaneous integrated boost with equivalent-doses-in-2-Gy-fractions (EQD-2) of $79.29 \mathrm{~Gy}$ or $71.43 \mathrm{~Gy}$ to the prostate bed was applied in patients with margin-positive (or detectable) and margin-negative/undetectable tumors, respectively. WPRT (44 Gy) was offered to patients at an increased risk of lymph node metastases.

Results: Forty-three patients with PBRT/WPRT and 77 with PBRT-only were identified. Baseline imbalances included shorter surgery-radiotherapy intervals (S-RT-Intervals) and fewer resected lymph nodes in the WPRT group. WPRT was significantly associated with better bPFS in univariate $(p=0.032)$ and multivariate models $(H R=0.484, p=$ 0.015). Subgroup analysis indicated a benefit of WPRT $(p=0.029)$ in patients treated with rising PSA values who mostly had negative margins (74.1\%); WPRT was not associated with a longer bPFS in the postoperative setting with almost exclusively positive margins (96.8\%).
\end{abstract}

Conclusion: We observed a longer bPFS after WPRT compared to PBRT in patients with locally advanced prostate carcinoma who underwent dose-escalated radiotherapy. In subset analyses, the association was only observed in patients with rising PSA values but not in patients with non-salvage postoperative radiotherapy for positive margins.

Keywords: Prostate carcinoma, Elective nodal irradiation, Salvage radiotherapy, Adjuvant radiotherapy

\footnotetext{
* Correspondence: daniel.buergy@medma.uni-heidelberg.de

${ }^{+}$Carola Link and Patrick Honeck contributed equally to this work.

${ }^{1}$ Department of Radiation Oncology, Universitätsmedizin Mannheim, Medical

Faculty Mannheim, Heidelberg University, Mannheim, Germany

${ }^{6}$ Heinrich-Lanz-Center for Digital Medicine, Medical Faculty Mannheim,

University of Heidelberg, Mannheim, Germany

Full list of author information is available at the end of the article
}

(c) The Author(s). 2019 Open Access This article is distributed under the terms of the Creative Commons Attribution 4.0 International License (http://creativecommons.org/licenses/by/4.0/), which permits unrestricted use, distribution, and reproduction in any medium, provided you give appropriate credit to the original author(s) and the source, provide a link to the Creative Commons license, and indicate if changes were made. The Creative Commons Public Domain Dedication waiver (http://creativecommons.org/publicdomain/zero/1.0/) applies to the data made available in this article, unless otherwise stated. 


\section{Background}

Post-prostatectomy radiotherapy can be given as adjuvant [1-3] or salvage [4] treatment with or without androgendeprivation therapy (ADT) $[5,6]$. The addition of ADT has just recently been shown to improve biochemical progression-free survival (bPFS) [5] and also overall survival (OS) after longer follow-up [6] when added to moderate-dose radiation therapy (66 and $64.8 \mathrm{~Gy}$, respectively, at the lower end of most recent EU and US guideline recommendations ( $\geq 66$ and $\geq 64-65$ Gy $[7,8])$ ). Although an optimal dose has not been established for salvage or adjuvant radiotherapy, some series indicate that doses > 70 Gy might improve bPFS [7-12]; however, dose escalation was associated with increased risk of toxicity even in recent series using highly conformal techniques such as intensity-modulated radiotherapy (IMRT) [13-15].

Aside from dose escalation and addition of $\mathrm{ADT}$, there is ongoing discussion about the effect of elective wholepelvic radiotherapy (WPRT). Despite negative studies in the primary setting $[16,17]$ and an absence of evidence in the post-prostatectomy situation at the time when the survey was conducted, WPRT has been considered by $74 \%$ of radiation oncologists in the salvage setting [18]. Interim results from the 3-arm randomized NRGOncology/RTOG-0534 trial support this approach; the study recently reported a bPFS benefit in the salvage setting by adding ADT or ADT plus WPRT to prostate bed ("fossa-only"; PBRT) irradiation [19].

We primarily conducted this study to analyze outcomes of patients with locally advanced but lymphnode-negative tumors (T3-4/N0) treated with two standardized, dose-escalated (71.43-79.29 Gy equivalentdoses-in-2-Gy-fractions, EQD-2) post-prostatectomy radiotherapy strategies with or without WPRT (44Gy, EQD-2 with volumes in line with RTOG recommendations [20]). Supplementary analyses were done as a pooled cohort with all node-negative patients (including T1-2/N0) and with node-positive patients (N1); however, both groups were not included in the main model due to extreme imbalances of PBRT and WPRT usage.

\section{Methods}

\section{Patients}

Following institutional review board approval (2018-509 $\mathrm{N}-\mathrm{MA}$ ), we analyzed charts of 244 patients that were treated between 01/2009 and 07/2017 ( $\geq 6$ months follow-up) with postoperative (salvage or adjuvant) radiotherapy to the prostate bed region (for in- and exclusion criteria see Additional file 1: Figure S1). In short, patients with locally advanced, node-negative (T3-4/N0) cancers were eligible in the post-prostatectomy setting irrespective of laparoscopic/robotic or open surgery or extent of lymph node resection. Patients with localized tumors $(\mathrm{T} 1-2 / \mathrm{N} 0)$ were not included in the main model as only 8 out of 52 patients had received WPRT (15.4\%); whereas almost all patients with node-positive disease had received WPRT (38 out of 40; 95\%); therefore, pooled analyses including those two groups were deemed exploratory and are reported in the supplementary appendix.

\section{Radiotherapy}

The clinical target volume-1 (CTV-1) included prostate bed, bladder neck, and urethral anastomosis regions in accordance with the Princess Margaret Hospital guidelines [21]. The seminal vesicle bed was always included in CTV-1 [22]. CTV-2 included prostate bed, bladder neck and anastomosis but not necessarily the seminal vesicle bed; both CTVs included localizable disease. Out of CTV-1/2, PTV-1/2 were created using a margin of 3$8 \mathrm{~mm}$. PTV-1 and PTV-2 were always irradiated with 60 Gy in 30 fractions. Patients without localizable tumors then received an additional dose of 6-7 Gy to PTV-1 plus $10 \mathrm{~Gy}$ as a 4-fraction simultaneous integrated boost (SIB) to PTV-2. Patients with detectable tumor manifestations (positive imaging or positive margins) received a 5-fraction SIB of 11-12 Gy to PTV-1 and 15 Gy to PTV2 . Assuming an $\alpha / \beta$ of 1.5 , this would result in an EQD2 to PTV-1 of 73.37 or 66.5 Gy and PTV-2 doses of 79.29 Gy ("high-dose cohort") or 71.43 Gy ("lower-dose cohort") for patients with detectable and undetectable disease, respectively.

SIB fractions were always applied as IMRT (or Volumetric Modulated Arc Therapy, VMAT) using daily image-guidance (IGRT) with cone-beam computed tomography $(\mathrm{CBCT})$. The initial 60 Gy were either given as a 3D-conformal or as an IMRT/VMAT-based approach.

Elective nodal irradiation with 44 Gy in 22 fractions was offered to patients with increased risk of nodal involvement. The latter was determined using surgically removed nodes: In case of N0 with $\geq 10$ negative nodes, pelvic radiation was not recommended. In case of $<10$ evaluable nodes and a Roach score [23] of $\geq 15$ (before 2012) or $\geq 25$ after adjustment in 2012, elective pelvic radiotherapy was offered to patients. For elderly patients ( $\geq 70$ years) WPRT was offered in case geriatric assessment yielded a favorable profile; otherwise, PBRT was recommended using high- or lower-dose approaches as described. Due to the lack of definitive evidence, we always accepted the patient's decision in favor or against pelvic radiotherapy after careful discussion of the evidence.

Pelvic target volumes were defined similar to the RTOG recommendations [20]; briefly, the superior border was the L5/S1 interspace (in case of positive nodes: L4/L5), the pubic symphysis was the anterior, and the lower aspect of the obturator foramen the inferior border. Dose constraints 
were in line with QUANTEC [24] recommendations for bladder, rectal, and bowel doses.

Concurrent ADT was used on an individual basis in our department prior to the publication of the GETUGAFU-16 [5] trial and the RTOG-9601 [6] study. After publication of the results, we discussed the possibility of concurrent ADT with all patients who had postoperative radiotherapy; for this analysis, patients who had received concurrent ADT were not excluded.

\section{Statistical calculations}

All analyses were performed using SPSS (V15.0), or "R", a language and environment for statistical computing. Survival curves were computed using the Kaplan-Meier approach; log-rank tests were used to calculate univariate associations with survival. Univariately associated variables entered a multivariate stepwise Cox regression model to identify independent predictors.

To address (unrelated) death as a confounder, bPFS analyses were complemented by freedom from biochemical failure (FFBF) analyses in which death events were censored. This was done to account for the increased risk of death in elderly patients as a potential confounder for bPFS.

\section{Results}

\section{Patient characteristics}

Baseline characteristics and differences between WPRT $(n=43)$, and PBRT $(n=77)$ patients are shown in Table 1. The median follow-up time was 62.2 months (range: 8.5-106.5 months). In the whole cohort of 120 locally advanced patients, average bPFS was 54.6 (95\%CI 46.3-62.9; median: 46.9) months and FFBF was 56.2 (47.8-64.6; median: 51.4) months.

\section{Radiotherapy factors univariately associated with bPFS or FFBF}

WPRT was significantly associated with bPFS $(p=0.032)$ and FFBF $(p=0.033)$ in univariate analysis (see Fig. 1a-b and Table 1 for details on baseline imbalances).

Dose escalation (79.29 vs. 71.43 Gy EQD-2) was performed in patients with identifiable tumors, defined as positive margins with known localization or detectable via MRI or PET-CT; therefore, $93.6 \%$ of high-dose patients had positive margins compared to $4.8 \%$ in the lower-dose cohort and, vice versa, $97.3 \%$ of margin-positive patients had received high doses. Furthermore, $95.2 \%$ of patients with lower-dose radiotherapy had salvage treatment compared to $23.1 \%$ of patients with high-dose radiotherapy $(p<0.001)$. Due to these imbalances, it is impossible to distinguish benefits associated with dose escalation $(p<$ 0.001 for bPFS and FFBF; Fig. 2a-b) from benefits associated with positive margins [25] or benefits from a negative risk selection in salvage patients (patients in the postoperative setting may not progress despite risk factors, even without treatment [1-3]); accordingly, salvage vs. postoperative radiotherapy was associated with shorter bPFS and FFBF (both $p<0.001$; Additional file 2: Figure S2a-b). We observed a trend for an improved bPFS ( $p=$ $0.055)$ and significantly improved $\operatorname{FFBF}(p=0.037)$ in patients with shorter S-RT-Intervals ( $<4$ months).

Only 13 patients (11\%) had received ADT which was associated with a numerical but not significant benefit in bPFS (Additional file 3: Figure S3a-b). Duration of concurrent ADT-usage was heterogeneous in our patient cohort with 6 patients receiving 6 months, which was the minimum duration, a median of 12 months and a maximum of 57.6 months.

\section{Other factors univariately associated with bPFS or FFBF}

Post-surgery, pre-radiotherapy PSA values of $\geq 0.2 \mathrm{ng} / \mathrm{ml}$ were associated with decreased bPFS and FFBF $(p=$ 0.022 and $p=0.012$; Additional file 4: Figure S4a-b; a higher PSA cut-off of $0.5 \mathrm{ng} / \mathrm{ml}$ was also associated with bPFS and FFBF: $p=0.049$ and $p=0.022$ ). Elderly patients ( $\geq 70$ years) did not have a significantly different bPFS $(p=0.101)$ but a trend towards shorter FFBF $(p=$ $0.066)$. Initial, i.e. preoperative PSA values $(<10,10-20$, $\geq 20 \mathrm{ng} / \mathrm{ml}$ ) were not associated with bPFS or FFBF after radiotherapy ( $p>0.1$ for all comparisons). Gleason scores of surgical specimens were significantly associated with bPFS $(p=0.003)$ and FFBF $(p=0.008$; Gleason 8 10 vs. Gleason 6-7; Additional file 4: Figure S4c-d). Roach scores at a cut-off of 15 were not associated with bPFS or FFBF; however, only 21 patients $(17.5 \%)$ in this advanced patient cohort had Roach scores of $<15$. For Roach scores $\geq 25$, there was a significantly decreased bPFS but only a trend for worse FFBF ( $p=0.043$ and $p=0.085$, respectively; Additional file 4: Figure S4e-f).

\section{Multivariate models}

Multivariate Cox models are shown in Table 2 and Table 3 ; based on available evidence $[5,6,19]$, we decided to enter concurrent ADT-usage into the models despite the insignificant findings in the univariate model which may have been caused by the low number of patients in the ADT-usage group $(n=13)$. Higher Gleason scores were independently associated with shorter and WPRT was independently associated with longer bPFS and FFBF, respectively. High-dose radiotherapy (used in patients with positive margins or detectable disease) showed a trend towards longer bPFS and FFBF ( $p=0.064$ and $p=0.073$ ) . Significant predictors in Table 2 and Table 3 remained significant when ADT-usage was excluded as a variable and/or Roach scores (cut-off 25) were used instead of or in addition to Gleason scores. 
Table 1 Baseline characteristics of 120 patients with locally advanced tumors who received fossa-only $(n=77)$ or elective pelvic nodal irradiation (WPRT; $n=43$ )

\begin{tabular}{|c|c|c|c|}
\hline Baseline Characteristics & Fossa-only $(n=77)$ & WPRT $(n=43)$ & Difference \\
\hline \multicolumn{4}{|c|}{ Age at radiation therapy in years } \\
\hline Mean & 66.9 & 66.9 & \multirow[t]{2}{*}{$p=0.98$} \\
\hline Standard deviation & 7.5 & 6.5 & \\
\hline \multicolumn{4}{|l|}{ Initial PSA value in ng/ml } \\
\hline Mean & 18.1 & 18.6 & \multirow[t]{2}{*}{$p=0.927$} \\
\hline Standard deviation & 26.8 & 18.0 & \\
\hline \multicolumn{4}{|c|}{ Gleason score (surgical specimens, No., percentage) } \\
\hline Gleason 6 & $2(2.6 \%)$ & 0 & \multirow{6}{*}{$p=0.087^{\S}$} \\
\hline Gleason 7a & $15(19.5 \%)$ & $9(20.9 \%)$ & \\
\hline Gleason 7b & $30(39.0 \%)$ & $10(23.3 \%)$ & \\
\hline Gleason 8 & $7(9.1 \%)$ & $4(9.3 \%)$ & \\
\hline Gleason 9 & $22(28.6 \%)$ & $19(44.2 \%)$ & \\
\hline Gleason 10 & $1(1.3 \%)$ & $1(2.3 \%)$ & \\
\hline \multicolumn{4}{|c|}{ Surgical margin (No., percentage) } \\
\hline RO & $29(37.7 \%)$ & $16(37.2 \%)$ & \multirow[t]{3}{*}{$p=1.0$} \\
\hline R1 & $48(62.3 \%)$ & $27(62.8 \%)$ & \\
\hline R2 & - & - & \\
\hline \multicolumn{4}{|c|}{ Dose level (Gy, prescribed dose, EQD-2 to PTV-2) } \\
\hline Lower-dose (71.43 Gy) & $29(37.7 \%)$ & $13(30.2 \%)$ & \multirow[t]{2}{*}{$p=0.433$} \\
\hline High-dose (79.29 Gy) & $48(62.3 \%)$ & $30(69.8 \%)$ & \\
\hline \multicolumn{4}{|c|}{ Time from surgery to radiation therapy (S-RT-Interval in months) } \\
\hline Mean & 13.3 & 6.1 & \multirow[t]{3}{*}{$p=0.003^{\#}$} \\
\hline Median & 5.1 & 3.6 & \\
\hline Standard deviation & 18.7 & 6.2 & \\
\hline \multicolumn{4}{|c|}{ Salvage or postoperative (adjuvant or R1) treatment indication (No., percentage) } \\
\hline Salvage & $41(53.2 \%)$ & $17(39.5 \%)$ & \multirow[t]{2}{*}{$p=0.184$} \\
\hline Postoperative & $36(46.8 \%)$ & $26(60.5 \%)$ & \\
\hline \multicolumn{4}{|l|}{ Roach scores } \\
\hline Mean & 28.9 & 32.8 & \multirow[t]{2}{*}{$p=0.27$} \\
\hline Standard deviation & 20.8 & 15.0 & \\
\hline \multicolumn{4}{|c|}{ Concurrent androgen deprivation therapy (ADT) } \\
\hline Yes & $7(9.1 \%)$ & $6(14 \%)$ & \multirow[t]{2}{*}{$p=0.541$} \\
\hline No & $70(90.9 \%)$ & $37(86 \%)$ & \\
\hline \multicolumn{4}{|c|}{ Pathologically identified number of lymph nodes (all N0) } \\
\hline Mean & 11.0 & 5.9 & \multirow[t]{4}{*}{$p<0.001^{\dagger}$} \\
\hline Standard deviation & 6.5 & 3.9 & \\
\hline$\geq 10$ nodes identified & $42(54.5 \%)$ & $2(4.7 \%)$ & \\
\hline$<10$ nodes identified & $35(45.5 \%)$ & $41(95.3 \%)$ & \\
\hline \multicolumn{4}{|c|}{ Post-surgery PSA at start of radiotherapy (if available) in $\mathrm{ng} / \mathrm{ml}$} \\
\hline Mean & 0.73 & 0.71 & \multirow[t]{2}{*}{$p=0.958$} \\
\hline Standard deviation & 1.62 & 1.66 & \\
\hline \multicolumn{4}{|c|}{ Laparoscopic or retropubic surgery } \\
\hline Laparoscopic & $31(40.3 \%)$ & $23(53.5 \%)$ & $p=0.184$ \\
\hline
\end{tabular}


Table 1 Baseline characteristics of 120 patients with locally advanced tumors who received fossa-only $(n=77)$ or elective pelvic nodal irradiation (WPRT; $n=43$ ) (Continued)

\begin{tabular}{lll}
\hline Baseline Characteristics & Fossa-only $(n=77)$ & WPRT $(n=43)$ \\
\hline Retropubic & $46(59.7 \%)$ & $20(46.5 \%)$ \\
\hline
\end{tabular}

${ }^{\S}$ Fisher's exact test, 2-sided for Gleason scores dichotomized at 7 (6-7 vs. 8-10); one-sided testing results in $p=0.056$ for an increased Gleason score in the WPRT group

"The baseline imbalance was significant using the independent samples T-test; imbalance was mainly due to outliers (non-parametric testing did not show a significant difference: $p=0.07$ for Mann-Whitney U-Test

${ }^{+}$WPRT was not routinely recommended in patients with $\geq 10$ lymph nodes resected and only performed in two cases after careful discussion with patients. If no lymph node dissection was performed, the number was scored as zero

\section{Salvage and postoperative subgroups with or without detectable disease}

To analyze if the association of WPRT with FFBF and bPFS observed in the whole cohort was present in both the salvage and postoperative (including adjuvant) setting, we performed subgroup analyses: WPRT was significantly associated with FFBF and bPFS in the salvage setting ( $p=0.029$ for bPFS and $p=0.039$ for FFBF; Additional file 5: Figure S5a-b) but there was no difference when radiotherapy was applied postoperatively without confirmed rise in PSA ( $p=0.616$ for bPFS and $p=0.56$ for FFBF; Additional file 5: Figure S5c-d). However, this analysis is confounded by our treatment approach: Most patients (96.8\%) treated postoperatively had positive margins and patients with positive margins had dose escalation in almost all cases (97.3\%); vice versa, patients treated in the salvage setting had mostly negative margins $(74.1 \%)$ and the lower-dose approach (69\%) for undetectable disease and negative margins. Therefore, we cannot specify if WPRT was associated with FFBF and bPFS in this subgroup because of the salvage situation, mostly undetectable tumor localizations, lower doses to the prostate bed or because of a combination of these factors. Because of the lower numbers in the subgroups and the significant overlap of variables, a multivariate model was not applicable in the subgroups.

\section{Toxicity}

Grade $\geq 2$ toxicity occurred in 20 patients (16.7\%) with an increased risk in patients who received WPRT compared to PBRT $(p=0.005)$ and in patients who had 79.29 Gy compared to 71.43 Gy to the prostatic bed ( $p=$ 0.043). Patients who received low-dose radiotherapy without pelvic irradiation had the lowest grade $2+$ toxicity risk (3.4\%) followed by high-dose PBRT (12.5\%), low-dose WPRT (15.4\%) and high-dose WPRT (36.7\%). There was no grade 3 gastrointestinal toxicity and there were 10 cases of grade 3 genitourinary toxicity, five after WPRT/PBRT (11.6\%) and five after PBRT-only (6.5\%); all patients with grade 3 events had received 79.29 Gy; incontinence at baseline which worsened after irradiation counted as an event.

\section{Supplementary analysis including patients with localized or node-positive disease}

All details for the pooled patient cohort of node-negative patients which included patients with localized disease (49/52 high-risk, 3/52 intermediate risk) and the full cohort, including patients with node-positive disease $(n=40$; all M0) is shown in Additional file 7: Table S1 and Additional file 6: Figure S6. Briefly, WPRT was associated with better bPFS and FFBF in the pooled cohorts as well but it is unknown if results can be extrapolated to any subgroup other than locally advanced node-negative patients.

\section{Discussion}

With this study, we provide a retrospective analysis on the addition of WPRT to dose-escalated PBRT after prostatectomy for locally advanced node-negative tumors. Most available studies reported on patients treated with prostate bed doses ranging from 61.2-72 Gy [19, 26-30] with only two European series reporting on toxicity of higher-dose series (EQD-2: 75-77 Gy) [15, 31]. WPRT doses in recent studies ranged from 40 to $54 \mathrm{~Gy}$. WPRT was associated with a bPFS benefit in some studies [26, 29, 30] while others described an association limited to subgroups [28] or found no association at all $[27,32]$. The strongest but not yet fully published evidence so far in support of combining PBRT and WPRT comes from an interim analysis of the RTOG-0534/SPPORT trial which showed significantly different 5-year failure-free survival rates between PBRT, PBRT plus ADT and WPRT plus ADT arms of 71.7, 82.7 and $89.1 \%$, respectively. Additionally, a trend towards increased metastases-free survival was reported when WPRT plus ADT was compared to the PBRT arm without ADT $(p=0.014$; the 3 -arm trial requires a $P$ value of 0.0125 for one-sided significance [19]). The trial protocol allowed for doses between 64.8-70.2 Gy and (dose-) subgroup analyses have not yet been reported. Biochemical failure rates were calculated using the Phoenix definition (PSA $2 \mathrm{ng} / \mathrm{ml}$ above nadir or clinical progression); patients who initiated second salvage prior to this definition were censored. In our analysis, we used a definition of two PSA rises and counted patients who initiated second salvage as events, even if salvage was initiated after one increase in PSA levels. Our dose escalation strategy 
a Biochemical progression-free survival (bPFS) in T3-4/N0 patients who received whole pelvic radiotherapy (WPRT) or prostate bed radiotherapy (PBRT)

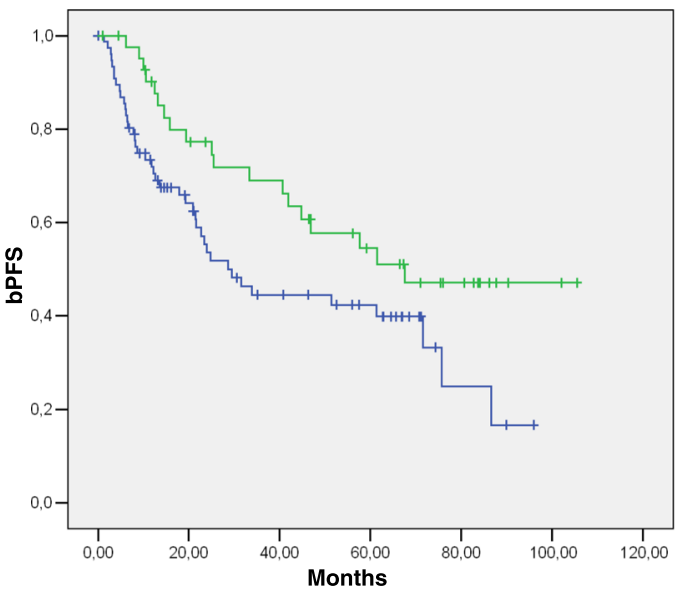

$$
\begin{aligned}
& \text { RT Field } \\
& \neg \text { PBRT } \\
& П \text { WPRT } \\
&++ \text { PBRT-censored } \\
&+ \text { WPRT-censored }
\end{aligned}
$$

No. at risk

No. at risk
\begin{tabular}{|l|c|c|c|c|c|c|c|}
\hline Months & $\mathbf{0}$ & $\mathbf{2 0}$ & $\mathbf{4 0}$ & $\mathbf{6 0}$ & $\mathbf{8 0}$ & $\mathbf{1 0 0}$ & $\mathbf{1 2 0}$ \\
\hline Fossa-only (PBRT) & 77 & 38 & 23 & 17 & 3 & 0 & 0 \\
\hline Whole pelvis (WPRT) & 43 & 30 & 25 & 16 & 5 & 2 & 0 \\
\hline
\end{tabular}

\section{b Freedom from biochemical failure (FFBF) T3-4/N0 patients who received whole} pelvic radiotherapy (WPRT) or prostate bed radiotherapy (PBRT)

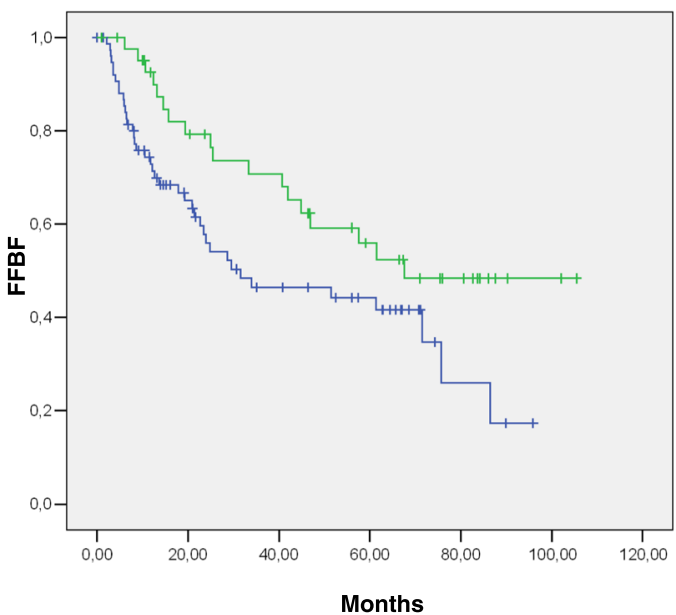

\section{RT Field \\ $\Pi$ PBRT \\ + PBRT-censored \\ + WPRT-censorec}

No. at risk

\begin{tabular}{|l|c|c|c|c|c|c|c|}
\hline Months & $\mathbf{0}$ & $\mathbf{2 0}$ & $\mathbf{4 0}$ & $\mathbf{6 0}$ & $\mathbf{8 0}$ & $\mathbf{1 0 0}$ & $\mathbf{1 2 0}$ \\
\hline Fossa-only (PBRT) & 77 & 38 & 23 & 17 & 3 & 0 & 0 \\
\hline Whole pelvis (WPRT) & 43 & 30 & 25 & 16 & 5 & 2 & 0 \\
\hline
\end{tabular}

Fig. 1) Biochemical progression-free survival (bPFS; 1a) and freedom from biochemical failure (FFBF; 1b) after whole-pelvic radiotherapy (WPRT) compared to fossa-only radiotherapy (PBRT) in patients with locally advanced node-negative prostate carcinomas after prostatectomy. Albeit not significantly different, the PBRT group included a higher percentage of patients with salvage indication (53.2\%) compared to the WPRT group (39.5\%); furthermore, patients were treated earlier after surgery in the WPRT group (6.1 months vs. 13.3 months, $p=0.003$ ) likely confounding these results in favor of WPRT. Other baseline imbalances are shown in Table 1. a Mean bPFS in the WPRT group was 66.4 months (95\%-Cl: 53.679.2 months; median: 67.6 months) and significantly longer ( $p=0.032$ ) compared to 44.7 months (95\%-Cl: 35.4-54.0 months; median: 28.7 months) in the PBRT group. b Mean FFBF in the WPRT group was 67.9 months (95\%-Cl: 55.1-80.7 months; median: 67.6 months) and significantly increased ( $p=0.033)$ compared to 46.1 months (95\%-Cl: 36.7-55.5 months; median: 31.5 months) in the PBRT group

does not allow for a quantification of the benefit associated with 79.29 Gy EQD-2 compared to 71.43 Gy EQD-2 because we cannot separate benefits associated with positive margins [25] from benefits of dose escalation which was almost exclusively used in margin-positive patients plus a minority $(6.4 \%)$ who received escalation after detection of recurrence in imaging (MRI as published [33] or PET-CT). Additionally, patients who received the higher 
a Biochemical progression-free survival (bPFS) in in T3-4/N0 patients who had received PBRT or PBRT/WPRT with high-dose radiotherapy (79.29 Gy for positive margins or detectable disease) compared lower-dose radiotherapy ( $71.43 \mathrm{~Gy}$ for undetectable disease) to the prostate bed.

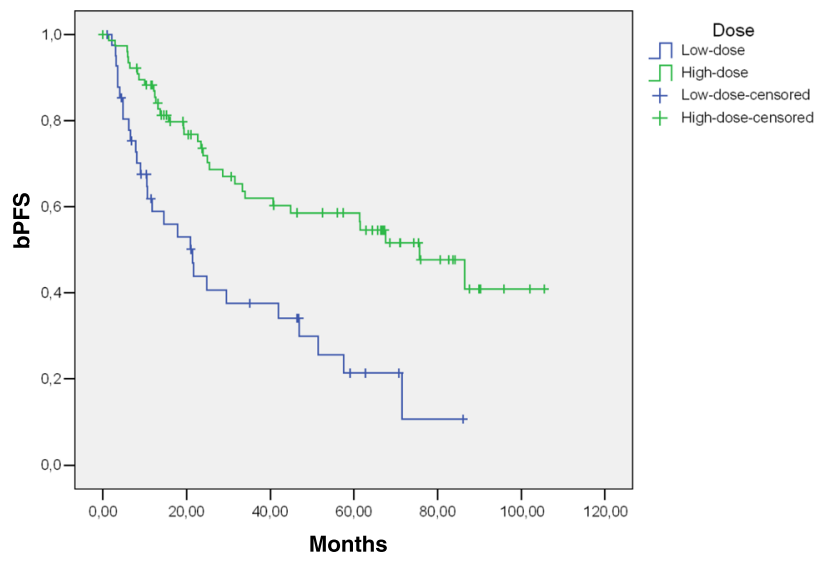

No. at risk
\begin{tabular}{|l|c|c|c|c|c|c|c|}
\hline Months & $\mathbf{0}$ & $\mathbf{2 0}$ & $\mathbf{4 0}$ & $\mathbf{6 0}$ & $\mathbf{8 0}$ & $\mathbf{1 0 0}$ & $\mathbf{1 2 0}$ \\
\hline High-dose & 78 & 50 & 37 & 29 & 11 & 2 & 0 \\
\hline Low-dose & 42 & 18 & 11 & 4 & 1 & 0 & 0 \\
\hline
\end{tabular}

b Freedom from biochemical failure (FFBF) in in T3-4/NO patients who had received PBRT or PBRT/WPRT with high-dose radiotherapy (79.29 Gy for positive margins or detectable disease) compared lower-dose radiotherapy ( $71.43 \mathrm{~Gy}$ for undetectable disease) to the prostate bed.

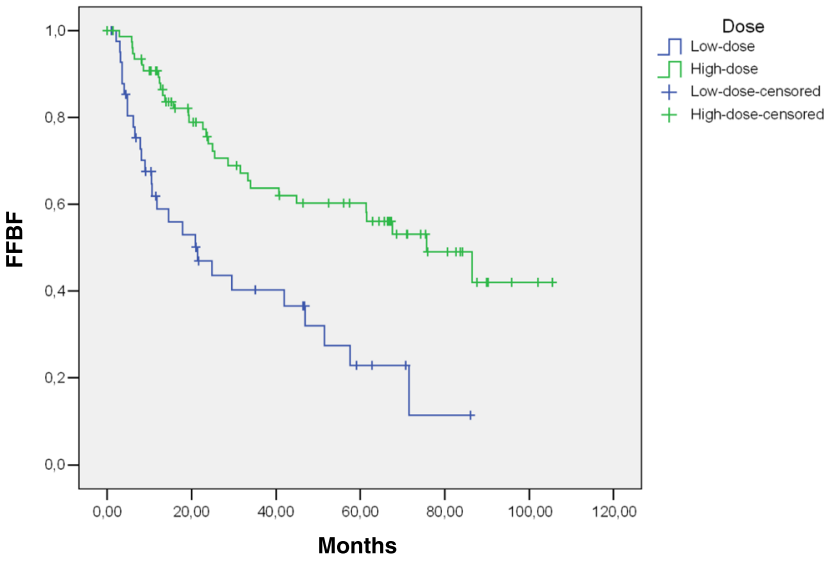

No. at risk

Months

\begin{tabular}{|l|c|c|c|c|c|c|c|}
\hline Months & $\mathbf{0}$ & $\mathbf{2 0}$ & $\mathbf{4 0}$ & $\mathbf{6 0}$ & $\mathbf{8 0}$ & $\mathbf{1 0 0}$ & $\mathbf{1 2 0}$ \\
\hline High-dose & 78 & 50 & 37 & 29 & 11 & 2 & 0 \\
\hline Low-dose & 42 & 18 & 11 & 4 & 1 & 0 & 0 \\
\hline
\end{tabular}

Fig. 2) Biochemical progression-free survival (bPFS; $2 \mathbf{a}$ ) and freedom from biochemical failure (FFBF; 2b) after high-dose radiotherapy (79.29 Gy) compared to lower-dose irradiation (71.43 Gy) in patients with locally advanced node-negative prostate carcinomas after prostatectomy who received PBRT-only or WPRT/PBRT. 93.6\% of high-dose patients had positive margins and $97.3 \%$ of margin-positive patients had high-dose irradiation. Furthermore, $95.2 \%$ of patients with lower-dose radiotherapy had salvage treatment compared to $23.1 \%$ of patients with high-dose radiotherapy $(p<0.001)$. Therefore, the benefit in bPFS and FFBF cannot be assigned to either positive margins, higher doses or treatment indication as it is highly likely that all factors independently contributed to the better outcomes. A multivariate model could not be applied due to the high overlap of high-dose patients with positive margins. a Mean bPFS in the high-dose (mostly R1/postoperative) group was 64.4 months (95\%-Cl: 54.3-74.5 months; median: 75.7 months) and significantly longer ( $p<0.001)$ compared to 32.2 months (95\%-Cl: $22.3-42.0$ months; median: 21.4 months) in the low-dose (R0/salvage) group. b Mean FFBF in the high-dose (R1/postoperative) group was 66.1 months (95\%-Cl: 56.0-76.2 months; median: 75.7 months) and significantly longer ( $p<0.001)$ compared to 33.4 months (95\%-Cl: $23.3-43.5$ months; median: 21.4 months) in the low-dose (mostly Ro/salvage) group 
Table 2 Multivariate survival model for biochemical progression-free survival (bPFS)

\begin{tabular}{|c|c|c|c|}
\hline Variable & Hazard Ratio & $95 \% \mathrm{Cl}$ & $P$ \\
\hline Elective pelvic radiotherapy (WPRT) & 0.484 & $0.270-0.870$ & 0.015 \\
\hline Detectable tumor and high-dose radiotherapy & 0.517 & $0.257-1.038$ & 0.064 \\
\hline Salvage radiotherapy ${ }^{c}$ & 1.444 & $0.704-2.962$ & 0.316 \\
\hline Androgen-deprivation therapy (ADT-) usage $\mathrm{e}^{\mathrm{a}}$ & 0.764 & $0.310-1.881$ & 0.558 \\
\hline PSA values at start of radiotherapy above $0.2 \mathrm{ng} / \mathrm{ml}$ & 1.503 & $0.850-2.658$ & 0.161 \\
\hline Higher Gleason score of surgical specimens ${ }^{b}$ & 1.491 & $1.128-1.973$ & 0.005 \\
\hline
\end{tabular}

${ }^{a}$ Excluding ADT-usage as a variable in a sensitivity model did not change results (i.e. WPRT and Gleason remained significant predictors)

busing the Roach score (cut-off of $\geq 25$ ) instead of Gleason scores did not change the overall model and did not influence WPRT as a significant predictor Inclusion of the S-RT-Interval which was not significant in the bPFS univariate model but in the FFBF analysis did not change the overall model and did not influence WPRT as a significant predictor

dose were mostly treated postoperatively (76.9\%) while $95.2 \%$ of patients with lower-dose treatment had a salvage strategy associated with a more unfavorable risk selection. Therefore, we did not attempt to quantify benefits of the two dose escalation levels but only analyzed benefits of WPRT in combination with PBRT at the high-dose-end of the currently used spectrum, the use of which was more evenly distributed across subgroups with fewer baseline imbalances as detailed in Table 1.

We found a 5-year bPFS benefit of 12.1\% (FFBF: 11.6\%) after WPRT/PBRT compared to PBRT-only which is higher compared to the $6.4 \%$ benefit observed in the RTOG-0534 dataset after WPRT and ADT vs. PBRT and ADT.

However, due to baseline imbalances and the retrospective nature of our analysis, the univariate model has to be interpreted with caution. Nevertheless, multivariate models showed a significant association of WPRT with longer bPFS and FFBF and thus, for the analyzed cohort, confirms the preliminary results of RTOG-0534. This was also true for the pooled patient cohort which includes patients who did not have advanced disease and the full cohort which also included node-positive patients (T1-4/ N0-1; all M0); however, as mentioned it is uncertain if the associations of WPRT with outcomes can be extrapolated to any subgroup other than locally advanced, nodenegative patients in our cohort because almost all patients with positive nodes were treated with WPRT while only 8 patients with T1-2/N0 tumors had WPRT.

Interestingly, the association of WPRT with longer bPFS in our cohort was consistent in the subgroup of patients who had salvage radiotherapy but not in patients with postoperative/adjuvant strategy. We cannot determine if the benefit of WPRT occurred because of a worse risk selection due to the salvage situation, the negative margin situation or the lower dose approach, as these factors overlapped. Likely, patients with negative margins, negative imaging and rising PSA values will have a higher risk of (undetected) microscopic disease in the lymph nodes compared to patients with an identifiable lesion (including R1) which explains rising or stable PSA values. Based on our dataset, the benefit of larger fields may be smaller in patients with positive margins. This hypothesis is in line with the previously reported improved outcomes for patients with positive margins in the adjuvant settings using PBRT [34, 35] and in the nomogram published by Tendulkar et al. for the salvage [25] situation (83\% of patients had PBRT). In patients with rising PSA values and an identifiable lesion, the risk of an occult (second) lesion may be lower compared to the risk in patients without any identified lesion explaining rising PSA values. However, this hypothesis cannot be ascertained with our dataset and we look forward to

Table 3 Multivariate survival model for freedom from biochemical failure (FFBF); death unrelated to prostate carcinoma was censored and not counted as an event

\begin{tabular}{|c|c|c|c|}
\hline Variable & Hazard Ratio & $95 \% \mathrm{Cl}$ & $P$ \\
\hline Elective pelvic radiotherapy (WPRT) & $\underline{0.493}$ & $0.270-0.898$ & 0.021 \\
\hline Detectable tumor and high-dose radiotherapy & 0.525 & $0.259-1.063$ & 0.073 \\
\hline Salvage radiotherapy ${ }^{c}$ & 1.547 & $0.745-3.215$ & 0.242 \\
\hline Androgen-deprivation therapy (ADT-) usage ${ }^{a}$ & 0.673 & $0.254-1.786$ & 0.427 \\
\hline PSA values at start of radiotherapy above $0.2 \mathrm{ng} / \mathrm{ml}$ & 1.631 & $0.904-2.943$ & 0.104 \\
\hline Higher Gleason score of surgical specimens ${ }^{b}$ & 1.441 & $1.080-1.922$ & 0.013 \\
\hline
\end{tabular}

${ }^{a}$ Excluding ADT-usage as a variable in a sensitivity model did not change results (i.e. WPRT and Gleason remained significant predictors)

${ }^{b}$ Using the Roach score (cut-off of $\geq 25$ ) instead of Gleason scores did not change the overall model and did not influence WPRT as a significant predictor Inclusion of the S-RT-Interval which was not significant in the bPFS univariate model but in the FFBF analysis did not change the overall model and did not influence WPRT as a significant predictor 
subgroup analysis of the RTOG-0534 trial which allowed for patients with positive or negative margins.

WPRT and dose escalation in our dataset were associated with a significantly increased risk of toxicity; furthermore, pelvic radiotherapy increased symptom burden and decision regret for radiotherapy (details will be reported separately). A higher risk of side effects has been described for dose-escalated radiotherapy in this setting even if most advanced techniques are applied [13-15]; furthermore, an increased incidence of toxicity following WPRT in line with our data has been reported previously [15]. For this reason, improved accuracy in the identification of patients who benefit from WPRT is mandatory.

Our study has several weaknesses; first, it is a retrospective analysis and therefore hypothesis-generating; second, it is uncertain if our data can be extrapolated to patients who received radiation doses below 70 Gy; third, ADT-usage was infrequent and duration was heterogeneous. Finally, we did not perform a patterns-of-recurrence analysis and did not systematically analyze imaging prior to inclusion; therefore, we do not know how many recurrences occurred in the pelvis and we cannot provide details on patients with selective dose escalation to lymph nodes after advanced imaging as they were excluded from the dataset. Despite these shortcomings our results indicate that WPRT was associated with longer bPFS and FFBF in patients with locally advanced node-negative prostate carcinoma who received radiotherapy to the prostatic bed after prostatectomy; although the result was significant in the whole patient group, subgroup analyses indicated that the benefit was more pronounced in patients with rising PSA values without detectable disease or positive margins. Our data together with the final results of RTOG-0534 will help to further refine patient selection in the postoperative/salvage setting.

\section{Conclusions}

We found a significant benefit in bPFS associated with WPRT in patients with locally advanced prostate carcinoma who underwent dose-escalated radiotherapy at the prostate bed. Incidence of grade $2+$ toxicity was higher in patients who had received WPRT or higher doses (79.29 Gy compared to $71.43 \mathrm{~Gy}$ ). In subset analyses, the association of WPRT with longer bPFS was only observed in patients with rising PSA values but not in patients with nonsalvage postoperative radiotherapy for positive margins. Taken together, our data indicate that there is a benefit of WPRT vs. PBRT in patients with rising PSA values.

\section{Additional files}

Additional file 1: Figure S1. CONSORT-like diagram, illustrating selection criteria for this retrospective analysis. (DOC $47 \mathrm{~kb}$ )
Additional file 2: Figure S2. (a-b) Univariate survival analyses showing postoperatively treated patients compared to patients with rising PSA values (salvage treatment). (DOCX $181 \mathrm{~kb}$ )

Additional file 3: Figure S3. (a-b) Univariate survival analyses of patients treated with or without concurrent ADT. (DOCX 178 kb)

Additional file 4: Figure S4. (a-b) Univariate survival analyses of patients with PSA values of $\geq 0.2 \mathrm{ng} / \mathrm{ml}$ compared to lower values. (c-d) Univariate survival analyses of patients with Gleason scores of 8-10 compared to Gleason 6-7 (surgical specimen). (e-f) Univariate survival analyses of patients with Roach scores of $\geq 25$ compared to lower scores. (DOCX 547 kb)

Additional file 5: Figure S5. (a-b) Univariate survival analyses of patients treated with WPRT and PBRT compared to PBRT only in the subgroup of patients with rising PSA values (salvage cohort). (c-d) Univariate survival analyses of patients treated with WPRT and PBRT compared to PBRT only in the subgroup of patients treated postoperatively without salvage indication. (DOCX $288 \mathrm{~kb}$ )

Additional file 6: Figure S6. Univariate survival analyses comparing FFBF and bPFS between the analysed cohort of patients with locally advanced tumors and patients with localized tumors and node-positive tumors at our department. (DOCX $373 \mathrm{~kb}$ )

Additional file 7: Table S1. This file shows multivariate models which include patients with localized disease and/or patients with node-positive tumors. (DOC $76 \mathrm{~kb}$ )

\section{Abbreviations}

ADT: Androgen depression therapy; bPFS: biochemical progression-free survival; CBCT: Cone-beam computed tomography; Cl: Confidence interval; CTV: Clinical target volume; EQD-2: Biologically-equivalent dose (in fractions of 2 Gy); FFBF: Freedom from biochemical failure; HR: Hazard ratio; IGRT: Image-guided radiation therapy; IMRT: Intensity-modulated radiation therapy; MRI: Magnetic resonance imaging; OS: Overall survival; PBRT: Radiotherapy of the prostatic fossa (without WPRT; fossa-only); PSA: Prostate-specific antigen; PTV: Planning target volume; SIB: Simultaneous integrated boost; S-RT-Interval: Interval between surgery and start of radiation therapy; VMAT: Volumetric Modulated Arc Therapy; WPRT: Elective pelvic nodal irradiation (in addition to PBRT)

\section{Acknowledgements \\ The support of participating patients and their families is gratefully acknowledged.}

\section{Authors' contributions}

$\mathrm{CL}$ contacted all patients and managed correspondence with patients during follow-up; AM provided assistance in the extraction of follow-up and treatment data. PH and CB performed radical prostatectomies and significantly contributed to writing the manuscript. FL established the SIB treatment concepts; FL and FW established image-guidance concepts, oversaw treatment planning and clinical treatments and provided assistance in writing the manuscript. JS and MB provided follow-up information. FG supported the final analysis and provided assistance in writing the manuscript. DB conceived the study, performed most of the statistical analysis and wrote the manuscript. All authors read and approved the final manuscript.

\section{Funding}

DB has been supported by the Forschungscampus $M^{2} O L I E$, funded by the German Federal Ministry of Education and Research (BMBF) within the Framework "Research Campus - public-private partnership for Innovation" under the funding code 13GW0090C.

\section{Availability of data and materials}

The dataset generated and analyzed during the current study are available from the corresponding author on reasonable request.

\section{Ethics approval and consent to participate}

The study was approved by the ethics committee of Heidelberg University, Medical Faculty Mannheim (2018-509 N-MA). Written informed consent for scientific usage of clinical data was obtained from all patients. 


\section{Consent for publication}

Consent for scientific usage of clinical data was obtained from all patients included in the study.

\section{Competing interests}

$\mathrm{CL}, \mathrm{PH}, \mathrm{AM}, \mathrm{FL}, \mathrm{JS}$, and $\mathrm{MB}$ have nothing to disclose; $\mathrm{CB}$ reports personal fees from medac $\mathrm{GmbH}$, personal fees from Janssen, personal fees from AstraZeneca, personal fees and other from Roche AG, grants and nonfinancial support from Erbe Elektromedizin $\mathrm{GmbH}$, outside the submitted work; FG reports grants and personal fees from NOXXON Pharma AG, grants and personal fees from CARL ZEISS MEDITEC AG, personal fees from BristolMyers Squibb, personal fees from Roche Pharma AG, personal fees from MSD Sharp and Dohme $\mathrm{GmbH}$, personal fees from AstraZeneca $\mathrm{GmbH}$, other from Implacit $\mathrm{GmbH}$, non-financial support from Oncare $\mathrm{GmbH}$, outside the submitted work; FW reports grants and personal fees from Elekta AB, Sweden, personal fees from Roche Pharma AG, grants, personal fees and other from Carl Zeiss Meditec AG, personal fees from Celgene $\mathrm{GmbH}$, personal fees from Eli Lilly and Company, personal fees from Ipsen Pharma GmbH, outside the submitted work; DB reports personal fees from Siemens AG, personal fees from NB Capital Research GmbH, personal fees from NB Capital ApS, personal fees from b.e. Imaging GmbH outside the submitted work.

\section{Author details}

'Department of Radiation Oncology, Universitätsmedizin Mannheim, Medical Faculty Mannheim, Heidelberg University, Mannheim, Germany. ${ }^{2}$ Department of Urology, University Medical Center Mannheim, Medical Faculty Mannheim, University of Heidelberg, Mannheim, Germany. ${ }^{3}$ Department of Urology, University of Ulm, Ulm, Germany. ${ }^{4}$ Struttura Complessa di Radioterapia, Dipartimento di Oncologia, Azienda Universitario-Ospedaliera, Policlinico, Modena, Italy. ${ }^{5}$ Freiburg Medical Center, Freiburg, Germany.

${ }^{6}$ Heinrich-Lanz-Center for Digital Medicine, Medical Faculty Mannheim, University of Heidelberg, Mannheim, Germany.

\section{Received: 25 March 2019 Accepted: 22 May 2019} Published online: 07 June 2019

\section{References}

1. Bolla M, van Poppel H, Tombal B, Vekemans K, Da Pozzo L, de Reijke TM, Verbaeys A, Bosset JF, van Velthoven R, Colombel M, et al. Postoperative radiotherapy after radical prostatectomy for high-risk prostate cancer: longterm results of a randomised controlled trial (EORTC trial 22911). Lancet. 2012;380:2018-27.

2. Wiegel T, Bartkowiak D, Bottke D, Bronner C, Steiner U, Siegmann A, Golz R, Storkel S, Willich N, Semjonow A, et al. Adjuvant radiotherapy versus waitand-see after radical prostatectomy: 10-year follow-up of the ARO 96-02/ AUO AP 09/95 trial. Eur Urol. 2014;66:243-50.

3. Thompson IM, Tangen CM, Paradelo J, Lucia MS, Miller G, Troyer D, Messing E, Forman J, Chin J, Swanson G, et al. Adjuvant radiotherapy for pathological T3NOMO prostate cancer significantly reduces risk of metastases and improves survival: long-term followup of a randomized clinical trial. J Urol. 2009;181:956-62.

4. Stephenson AJ, Bolla M, Briganti A, Cozzarini C, Moul JW, Roach M 3rd, van Poppel H, Zietman A. Postoperative radiation therapy for pathologically advanced prostate cancer after radical prostatectomy. Eur Urol. 2012;61:443-51.

5. Carrie C, Hasbini A, de Laroche G, Richaud P, Guerif S, Latorzeff I, Supiot S, Bosset M, Lagrange JL, Beckendorf V, et al. Salvage radiotherapy with or without short-term hormone therapy for rising prostate-specific antigen concentration after radical prostatectomy (GETUG-AFU 16): a randomised, multicentre, open-label phase 3 trial. Lancet Oncol. 2016;17:747-56.

6. Shipley WU, Seiferheld W, Lukka HR, Major PP, Heney NM, Grignon DJ, Sartor O, Patel MP, Bahary JP, Zietman AL, et al. Radiation with or without antiandrogen therapy in recurrent prostate Cancer. N Engl J Med. 2017:376:417-28.

7. Cornford P, Bellmunt J, Bolla M, Briers E, De Santis M, Gross T, Henry AM, Joniau S, Lam TB, Mason MD, et al. EAU-ESTRO-SIOG guidelines on prostate Cancer. Part II: treatment of relapsing, metastatic, and castration-resistant prostate Cancer. Eur Urol. 2017;71:630-42.

8. Thompson IM, Valicenti RK, Albertsen P, Davis BJ, Goldenberg SL, Hahn C, Klein E, Michalski J, Roach M, Sartor O, et al. Adjuvant and salvage radiotherapy after prostatectomy: AUA/ASTRO guideline. J Urol. 2013;190:441-9.
9. King CR. The dose-response of salvage radiotherapy following radical prostatectomy: a systematic review and meta-analysis. Radiother Oncol. 2016;121:199-203.

10. Bernard JR Jr, Buskirk SJ, Heckman MG, Diehl NN, Ko SJ, Macdonald OK, Schild SE, Pisansky TM. Salvage radiotherapy for rising prostate-specific antigen levels after radical prostatectomy for prostate cancer: dose-response analysis. Int J Radiat Oncol Biol Phys. 2010;76:735-40.

11. King CR, Kapp DS. Radiotherapy after prostatectomy: is the evidence for dose escalation out there? Int J Radiat Oncol Biol Phys. 2008;71:346-50.

12. Cozzarini C, Montorsi F, Fiorino C, Alongi F, Bolognesi A, Da Pozzo LF, Guazzoni G, Freschi M, Roscigno M, Scattoni V, et al. Need for high radiation dose ( $>$ or $=70 \mathrm{gy}$ ) in early postoperative irradiation after radical prostatectomy: a single-institution analysis of 334 high-risk, node-negative patients. Int J Radiat Oncol Biol Phys. 2009;75:966-74.

13. Goenka A, Magsanoc JM, Pei X, Schechter M, Kollmeier M, Cox B, Scardino PT, Eastham JA, Zelefsky MJ. Improved toxicity profile following high-dose postprostatectomy salvage radiation therapy with intensity-modulated radiation therapy. Eur Urol. 2011;60:1142-8.

14. Ost $\mathrm{P}$, Lumen $\mathrm{N}$, Goessaert AS, Fonteyne V, De Troyer B, Jacobs F, De Meerleer G. High-dose salvage intensity-modulated radiotherapy with or without androgen deprivation after radical prostatectomy for rising or persisting prostate-specific antigen: 5-year results. Eur Urol. 2011;60:842-9.

15. Van Praet C, Ost P, Lumen N, De Meerleer G, Vandecasteele K, Villeirs G, Decaestecker K, Fonteyne V. Postoperative high-dose pelvic radiotherapy for $\mathrm{N}+$ prostate cancer: toxicity and matched case comparison with postoperative prostate bed-only radiotherapy. Radiother Oncol. 2013;109:222-8.

16. Pommier $P$, Chabaud S, Lagrange JL, Richaud $P$, Lesaunier F, Le Prise E, Wagner JP, Hay MH, Beckendorf V, Suchaud JP, et al. Is there a role for pelvic irradiation in localized prostate adenocarcinoma? Preliminary results of GETUG-01. J Clin Oncol. 2007;25:5366-73.

17. Roach M, Moughan J, Lawton CAF, Dicker AP, Zeitzer KL, Gore EM, Kwok Y, Seider MJ, Hsu IC, Hartford AC, et al. Sequence of hormonal therapy and radiotherapy field size in unfavourable, localised prostate cancer (NRG/RTOG 9413): long-term results of a randomised, phase 3 trial. Lancet Oncol. 2018;19:1504-15.

18. Moghanaki D, Urdaneta Al, Karlin JD, Koontz BF, Anscher MS. Management of Postprostatectomy Biochemical Relapse with Salvage Radiotherapy: results of an international survey. Am J Clin Oncol. 2016;39:64-8.

19. Pollack A, Karrison TG, Balogh AG, Low D, Bruner DW, Wefel JS, Gomella LG, Vigneault E, Michalski JM, Angyalfi S, et al. Short-term androgen deprivation therapy without or with pelvic lymph node treatment added to prostate bed only salvage radiotherapy: the NRG oncology/RTOG 0534 SPPORT trial (abstract LBA5). In: 2018 ASTRO annual meeting. San Antonio; 2018.

20. Lawton CA, Michalski J, El-Naqa I, Buyyounouski MK, Lee WR, Menard C, O'Meara E, Rosenthal SA, Ritter M, Seider M. RTOG GU radiation oncology specialists reach consensus on pelvic lymph node volumes for high-risk prostate cancer. Int J Radiat Oncol Biol Phys. 2009;74:383-7.

21. Wiltshire KL, Brock KK, Haider MA, Zwahlen D, Kong V, Chan E, Moseley J, Bayley A, Catton C, Chung PW, et al. Anatomic boundaries of the clinical target volume (prostate bed) after radical prostatectomy. Int J Radiat Oncol Biol Phys. 2007:69:1090-9.

22. Shelan M, Abo-Madyan Y, Welzel G, Bolenz C, Kosakowski J, Behnam N, Wenz F, Lohr F. Dose-escalated salvage radiotherapy after radical prostatectomy in high risk prostate cancer patients without hormone therapy: outcome, prognostic factors and late toxicity. Radiat Oncol. 2013;8:276.

23. Roach M 3rd, Marquez C, Yuo HS, Narayan P, Coleman L, Nseyo UO, Navvab $Z$, Carroll PR. Predicting the risk of lymph node involvement using the pretreatment prostate specific antigen and Gleason score in men with clinically localized prostate cancer. Int J Radiat Oncol Biol Phys. 1994;28:33-7.

24. Marks LB, Yorke ED, Jackson A, Ten Haken RK, Constine LS, Eisbruch A, Bentzen SM, Nam J, Deasy JO. Use of normal tissue complication probability models in the clinic. Int J Radiat Oncol Biol Phys. 2010;76:S10-9.

25. Tendulkar RD, Agrawal S, Gao T, Efstathiou JA, Pisansky TM, Michalski JM, Koontz BF, Hamstra DA, Feng FY, Liauw SL, et al. Contemporary update of a multi-institutional predictive nomogram for salvage radiotherapy after radical prostatectomy. J Clin Oncol. 2016;34:3648-54.

26. Ramey SJ, Agrawal S, Abramowitz MC, Moghanaki D, Pisansky TM, Efstathiou $J A$, Michalski JM, Spratt DE, Hearn JWD, Koontz BF, et al. Multi-institutional evaluation of elective nodal irradiation and/or androgen deprivation therapy with Postprostatectomy salvage radiotherapy for prostate Cancer. Eur Urol. 2018;74:99-106. 
27. Pisansky TM, Agrawal S, Hamstra DA, Koontz BF, Liauw SL, Efstathiou JA, Michalski JM, Feng FY, Abramowitz MC, Pollack A, et al. Salvage radiation therapy dose response for biochemical failure of prostate Cancer after prostatectomy-a multi-institutional observational study. Int J Radiat Oncol Biol Phys. 2016;96:1046-53.

28. Moghanaki D, Koontz BF, Karlin JD, Wan W, Mukhopadhay N, Hagan MP, Anscher MS. Elective irradiation of pelvic lymph nodes during postprostatectomy salvage radiotherapy. Cancer. 2013;119:52-60.

29. Song C, Kang HC, Kim JS, Eom KY, Kim IA, Chung JB, Hong SK, Byun SS, Lee SE. Elective pelvic versus prostate bed-only salvage radiotherapy following radical prostatectomy: a propensity score-matched analysis. Strahlenther Onkol. 2015;191:801-9.

30. Spiotto MT, Hancock SL, King CR. Radiotherapy after prostatectomy: improved biochemical relapse-free survival with whole pelvic compared with prostate bed only for high-risk patients. Int J Radiat Oncol Biol Phys. 2007;69:54-61.

31. Jereczek-Fossa BA, Ciardo D, Ferrario S, Fossati P, Fanetti G, Zerini D, Zannoni D, Fodor C, Gerardi MA, Surgo A, et al. No increase in toxicity of pelvic irradiation when intensity modulation is employed: clinical and dosimetric data of 208 patients treated with post-prostatectomy radiotherapy. Br J Radiol. 2016;89:20150985.

32. Saracino B, Petrongari MG, Marzi S, Bruzzaniti V, Sara G, Arcangeli S, Arcangeli G, Pinnaro P, Giordano C, Ferraro AM, Strigari L. Intensitymodulated pelvic radiation therapy and simultaneous integrated boost to the prostate area in patients with high-risk prostate cancer: a preliminary report of disease control. Cancer Med. 2014;3:1313-21.

33. Buergy D, Sertdemir M, Weidner A, Shelan M, Lohr F, Wenz F, Schoenberg SO, Attenberger UI. Detection of local recurrence with 3-tesla MRI after radical prostatectomy: a useful method for radiation treatment planning? In Vivo. 2018;32:125-31.

34. Van der Kwast TH, Bolla M, Van Poppel H, Van Cangh P, Vekemans K, Da Pozzo L, Bosset JF, Kurth KH, Schroder FH, Collette L. EORTC: identification of patients with prostate cancer who benefit from immediate postoperative radiotherapy: EORTC 22911. J Clin Oncol. 2007;25:4178-86.

35. Wiegel T, Bottke D, Steiner U, Siegmann A, Golz R, Storkel S, Willich N, Semjonow A, Souchon R, Stockle M, et al. Phase III postoperative adjuvant radiotherapy after radical prostatectomy compared with radical prostatectomy alone in $\mathrm{pT} 3$ prostate cancer with postoperative undetectable prostate-specific antigen: ARO 96-02/AUO AP 09/95. J Clin Oncol. 2009;27:2924-30.

\section{Publisher's Note}

Springer Nature remains neutral with regard to jurisdictional claims in published maps and institutional affiliations.

Ready to submit your research? Choose BMC and benefit from:

- fast, convenient online submission

- thorough peer review by experienced researchers in your field

- rapid publication on acceptance

- support for research data, including large and complex data types

- gold Open Access which fosters wider collaboration and increased citations

- maximum visibility for your research: over $100 \mathrm{M}$ website views per year

At $\mathrm{BMC}$, research is always in progress.

Learn more biomedcentral.com/submissions 